\title{
Two-dimensional left atrial and left ventricular function in asymptomatic diabetic patients
}

\section{(i) Fatmir Ferati*, (D)Anida Ferati ${ }^{2}$, (D)Mentor Karemani² \\ 'University Hospital Tetovo, Tetovo, Republic of Macedonia \\ ${ }^{2}$ Med-Artis, Tetovo, Republic} of Macedonia

RECEIVED:

August 20, 2018

ACCEPTED:

November 5, 2018

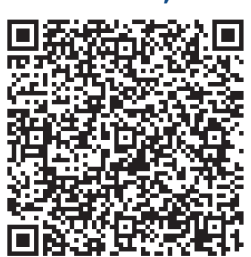

$\square$ Cardiologia Croatica 2018:13(11-12):408.
KEYWORDS: echocardiography, diabetes, left ventricular function

CITATION: Cardiol Croat. 2018;13(11-12):408. | https://doi.org/10.15836/ccar2018.408

*ADDRESS FOR CORRESPONDENCE: Fatmir Ferati, University Hospital Tetovo, Derish Cara bb, 1200 Tetovo, Republic of Macedonia. / Phone: +389-70-224138 / E-mail: fatmir_ferati@yahoo.com

ORCID: Fatmir Ferati, https://orcid.org/0000-0001-8189-316X·Anida Ferati, https://orcid.org/0000-0002-4243-5569 Mentor Karemani, https://orcid.org/0000-0001-6626-6504

|IIIIIIIIIIIIIIIIIIIIIIIIIIIIIIIIIIIIIIIIIIIIIIIIIIIIIIIIIIIIIIIIIIIIIIIIIIIIIIIIIIIIIIIIIIIIIIIIIIIIIIIIIIIIIIIIIIIIIIIIII

Introduction: The aim of the paper is the detection of changes in function of the left atrium (LA) and left ventricle (LV) in asymptomatic diabetic patients ${ }^{1}$, distinguished by the control group, using two-dimensional (2D) speckle tracking echocardiography.

Methods: 50 asymptomatic patients with diabetes mellitus were analyzed ( 28 males and 22 females) with an average age of 56,4 years ( $56 \pm 20$ years). In control group without verified disease, 50 individuals have been chosen randomly, 26 males and 24 females, with an average age of 55.3 years $(55.3 \pm 17)$.

Results and Conclusions: 1 . Decrease of 2D strain of left ventricle is registered in patients with diabetes, starting from the global longitudinal strain (GLS) (-21.79 vs. 16.7\%), myocardial longitudinal strain (LS) (17.69 vs $13.89 \%$ ) and global radial strain of LV (GRS) (51 vs 42.9\%) (Figure 1). 2. Minimal value from -17\% is registered of LS values at control group and from - $14.2 \%$ at diabetic group where registered $\mathbf{3}$. Extension of T2P (time to peak) longitudinal and transversal strain values in patients with diabetes is registered. 4. Increased value of LV mass at patients with diabetes is registered in our study (133 gr vs $123 \mathrm{gr}), \mathbf{5}$. Insignificant increase of LA volume is registered in diabetic group $\left(21,82 \mathrm{vs} 20,66 \mathrm{ml} / \mathrm{m}^{2}\right)$. $\mathbf{6}$. EF of LA is decreased in diabetic patient (55.69 vs 50.58\%) together with decrease fractional area contraction (FAC) of LA (69.56 vs 41.23\%) (Figure 2). 7. Decrease in values of end diastolic longitudinal strain (LS) of LA is registered in diabetic patients (48,78 vs 37.33\%) 8. LA strain rate (SR) of $\mathrm{E}$ wave is decreased in diabetic patient (1,84 vs 0,91), with smaller decrease of SR of A wave from (2.21 vs 1.97) 9. E/A SR relation is decreased in the diabetic patients vs control group $(0,83$ vs 0,43$) \mathbf{1 0}$. Decreased strain parameters of LV also decrease and LV compliance, which decrease the passive $E$ wave SR and increase active A SR phase of LA function.

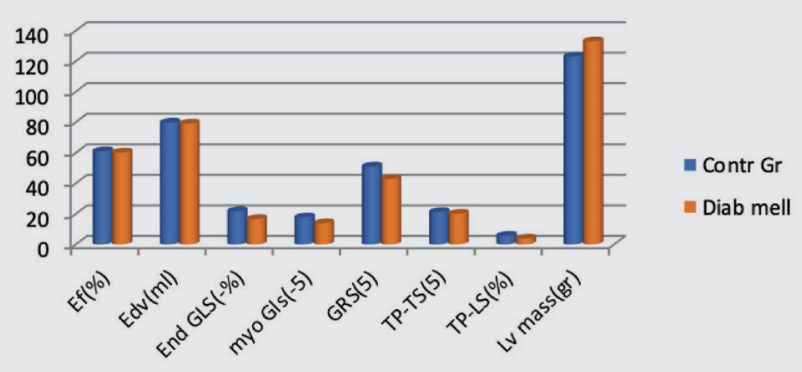

FIGURE 1. Left ventricular function assessment by two-dimensional echocardiography. ejection fraction (EF); end-diastolic volume (Edv); myocardial global strain of left ventricle (myo GLS); global radial strain of left ventricle (GRS); time to peak of transversal strain (TP-TS); time to peak long strain (TP-LS); left ventristrain of left ventricle (GRS); time to peak of transversal strain (TP-TS); time to peak long strain (TP.l)
cular mass (LV mass); control group (Contr Gr); group of patients with diabetes mellitus (Diab mell)

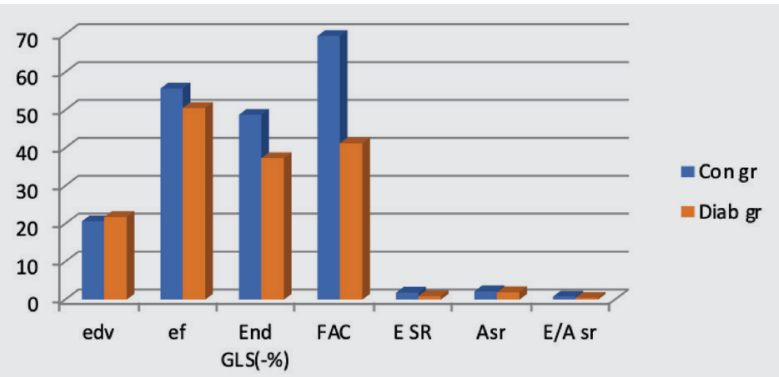

FIGURE 2. Left atrial function assessment by two-dimensional echocardiography. end-diastolic volume of left atrium (edv); ejection fraction of left atrium (ef); Endoc GLS (End GLS); fractional area contraction of left atrium (FAC); left atrial strain rate of Ewave (E SR); left atrial strain rate of A wave (Asr); E/A strain rate (E/A sr); control group (Con gr); group of patients with diabetes mellitus (Diab gr)

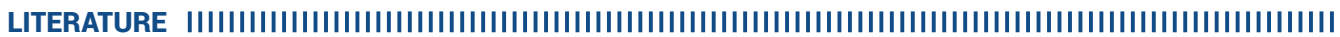

1. Atas H, Kepez A, Atas DB, Kanar BG, Dervisova R, Kivrak T, et al. Effects of diabetes mellitus on left atrial volume and functions in normotensive patients without symptomatic cardiovascular disease. J Diabetes Complications. 2014 Nov-Dec;28(6):858-62. https://doi.org/10.1016/j.jdiacomp.2014.07.010 